\title{
Spatio-Temporal Drought Characterization in Kenya from 1987 to 2016
}

\author{
Ruth Beth Mutsotso, Arthur W. Sichangi, Godfrey O. Makokha \\ Institute of Geomatics, GIS and Remote Sensing, Dedan Kimathi University of Technology, Nyeri, Kenya \\ Email: ruthmutsotso@yahoo.com
}

How to cite this paper: Mutsotso, R.B., Sichangi, A.W. and Makokha, G.O. (2018) Spatio-Temporal Drought Characterization in Kenya from 1987 to 2016. Advances in Remote Sensing, 7, 125-143. https://doi.org/10.4236/ars.2018.72009

Received: March 22, 2018

Accepted: June 26, 2018

Published: June 29, 2018

Copyright $\odot 2018$ by authors and Scientific Research Publishing Inc. This work is licensed under the Creative Commons Attribution International License (CC BY 4.0).

http://creativecommons.org/licenses/by/4.0/

\section{cc) (i) Open Access}

\begin{abstract}
Kenya is a drought, famine and hunger prone country, with considerable impact on agriculture, human health and livestock due to its eco-climatic conditions. It contains only a few regions of high and regular rainfall where arid and semi-arid lands cover $80 \%$ of the territory, therefore periodical droughts are part of the climate system. Some drought studies undertaken in Kenya used Standardized Precipitation Index (SPI) which could not fully account for drought severity status as the role of temperature increase on drought conditions was not taken into account. This study has tried to fill the gap by using Standardized Precipitation Evapotranspiration Index (SPEI), which includes precipitation, a temperature component and evapotranspiration in its computations. SPEI and the Normalized Difference Vegetation Index Anomaly (NDVI) were applied to characterize drought in Kenya from 1987 to 2016, investigate the drought severity and duration in the same period, assess drought trends together with mapping of spatial distribution of drought in identified months, assessment of Agricultural, meteorological and socio-economic activities. Correlation analysis was done to understand the response of climate and satellite based drought monitoring indices results and the crop yield data. The results and analysis obtained from the study showed that the years 1987, 1998, 2000, 2001, 2005, 2006, 2008, 2009, 2010, 2011 and 2015 were considered as drought years based on their SPEI and NDVI anomaly results. They were classified as extremely dry, very dry and moderately dry for meteorological drought and slight, moderate, severe and very severe for Agricultural drought. SPEI results can be rated as being superior as the element of temperature variation is taken into consideration.
\end{abstract}

\section{Keywords}

Meteorological Drought, Agricultural Drought, NDVI, SPEI 


\section{Introduction}

Drought is a water-related, most complex natural disaster which affects a wide range of environmental factors and activities related to agriculture, vegetation, human, wild life and local economies. More specific drought definitions are used around the world according to lack of rain over various time periods, or measured impacts such as reservoir levels or crop losses [1]. Drought usually involves a deficiency of precipitation that leads to reduced soil moisture and diminished plant growth when prolonged over longer periods of time [2]. Drought can also be defined according to meteorological, agricultural, hydrological, and socio-economic criteria [3]. Understanding drought occurrences serves as an early warning and provides approaches linked to mitigation of its impacts [4]. Major drought events have been reported in the USA, the Horn of Africa, Australia, and Southern Europe over the past few decades [5]. In many parts of the world, drought is a recurrent disaster and often the pre courser of famine [6]. Globally, drought $(7.5 \%)$ is the second-most geographically extensive hazard after floods (11\%) of the earth's land area [1]. The percent of area affected by serious drought has doubled from1970s to the early 2000 [7].

Africa is prone to a variety of hazards especially the occurrence of HydroMeteorological hazards (drought and floods). This has increased of recent with devastating impacts and has become more frequent in the $21^{\text {st }}$ century in sub-Saharan Africa (SSA) where droughts account for over $80 \%$ of the affected population [1]. Sub-Saharan Africa has suffered from many devastating droughts in recent history. Among some of the most devastating droughts globally during the past 50 years have been the Sahelian droughts of the 1970s and ' 80 s, which drove famine conditions over much of the region and led to an estimated 600,000 deaths [8] and [9] and droughts in 1991/92 in southern Africa. Multiyear droughts across the Horn of Africa [10] led to food shortages across the region and famine conditions in Somalia and northern Kenya.

Kenya being the study area has had drought episodes over the past five decades. The recently documented droughts occurred during 2008/2009 and 2010/2011, hitting the arid and semi-arid regions of the country hard [11]. It is therefore evident that Kenya has had extreme drought events whose spatial and temporal variability has not been understood, especially at regional and sub-regional scales.

The main purpose of this study was to characterize drought in Kenya from 1987 to 2016 using climatic data and satellite images. The study concentrated on the last three decades due to availability of remote sensing data and the interest in the recent developments of drought events in the study area. In this study Normalized Difference Vegetation Index (NDVI) and the Standardized Precipitation Evapotranspiration Index (SPEI) indices were used. NDVI Anomaly was applied to characterize agricultural drought, (SPEI) to characterize meteorological drought whereas maize production data was used to show the effects of climate change on socio economic activities in Kenya from the years 1987 to 2016. 
Several researches have been conducted with similar environmental topics using satellite and climate data and showed successful and satisfactory results.[12] in his research GIS-based climate variability and drought characterization in Ethiopia over three decades, used the STARDEX indices, and SPI for1-, 3-, 6- and 12 months' time scales to assess the erratic nature of rainfall in the study region. [13] used remote sensing (rainfall, vegetation condition index (VCI), terrestrial water storage (TWS), reanalysis (soil moisture and TWS), and land surface models (soil moisture). These products were employed to characterize East Africa droughts between 1983 and 2013 in terms of severity, duration, and spatial extent. [14] used GIS and Remote Sensing in Assessment of Water Scarcity in Nakuru County, Kenya. The main objective was to study Land use and Land cover area changes using Landsat satellite image data, standardised precipitation index (SPI) and crop yields.

Most of the studies carried out in Kenya, used Standardized Precipitation Index (SPI), which could not fully account for drought severity status as the role of temperature increase on drought conditions was not recognized. SPI is actually a precipitation-based drought index. This study has tried to fill the gap by using SPEI which includes precipitation, a temperature component and evapotranspiration in its computation. This has allowed the index to account for the effect of temperature on drought through a basic water balance calculation. This in effect has made the research more detailed and a better result.

\section{Methodology}

\subsection{Description of the Study Area}

The Republic of Kenya, lies between $5^{\circ} 7^{\prime} \mathrm{N}$ and $4^{\circ} 39^{\prime} \mathrm{S}$ longitude and is part of the Greater Horn of Africa along the Indian Ocean [15]. Figure 1 shows the location of the study area. Kenya has a population of approximately 40 million with nearly $22 \%$ of Kenyans living in urban centres [16]. It is bordered by Tanzania to the south, Uganda to the west, Ethiopia to the north, Sudan to the north-west, Somalia to the east, and the Indian Ocean to the South-East. Its area is approximately 584,000 square $\mathrm{km}$.

The country has climatic and ecological extremes with altitude varying from sea level to over $5000 \mathrm{~m}$ in the highlands. The mean annual rainfall ranges from less than $250 \mathrm{~mm}$ in semi-arid and arid areas to greater than $2000 \mathrm{~mm}$ in high potential areas. Soils vary from the coral types on the coast to alluvial, swampy, and black cotton soils along river valleys and plains. The Kenyan highlands have fertile volcanic soils whereas in the semi-arid regions are shallow and infertile. Farming is the primary livelihood of more than $75 \%$ of the population, conducted either on subsistence plots in marginal farming areas or on large plantations in the more arable areas [17], with less than $4 \%$ of people being pastoralists. One third of the total land area of Kenya is agriculturally productive, including the Kenyan highlands, coastal plains and the lake region. The other two thirds of the land area is semi-arid to arid and is characterized by low, unreliable 


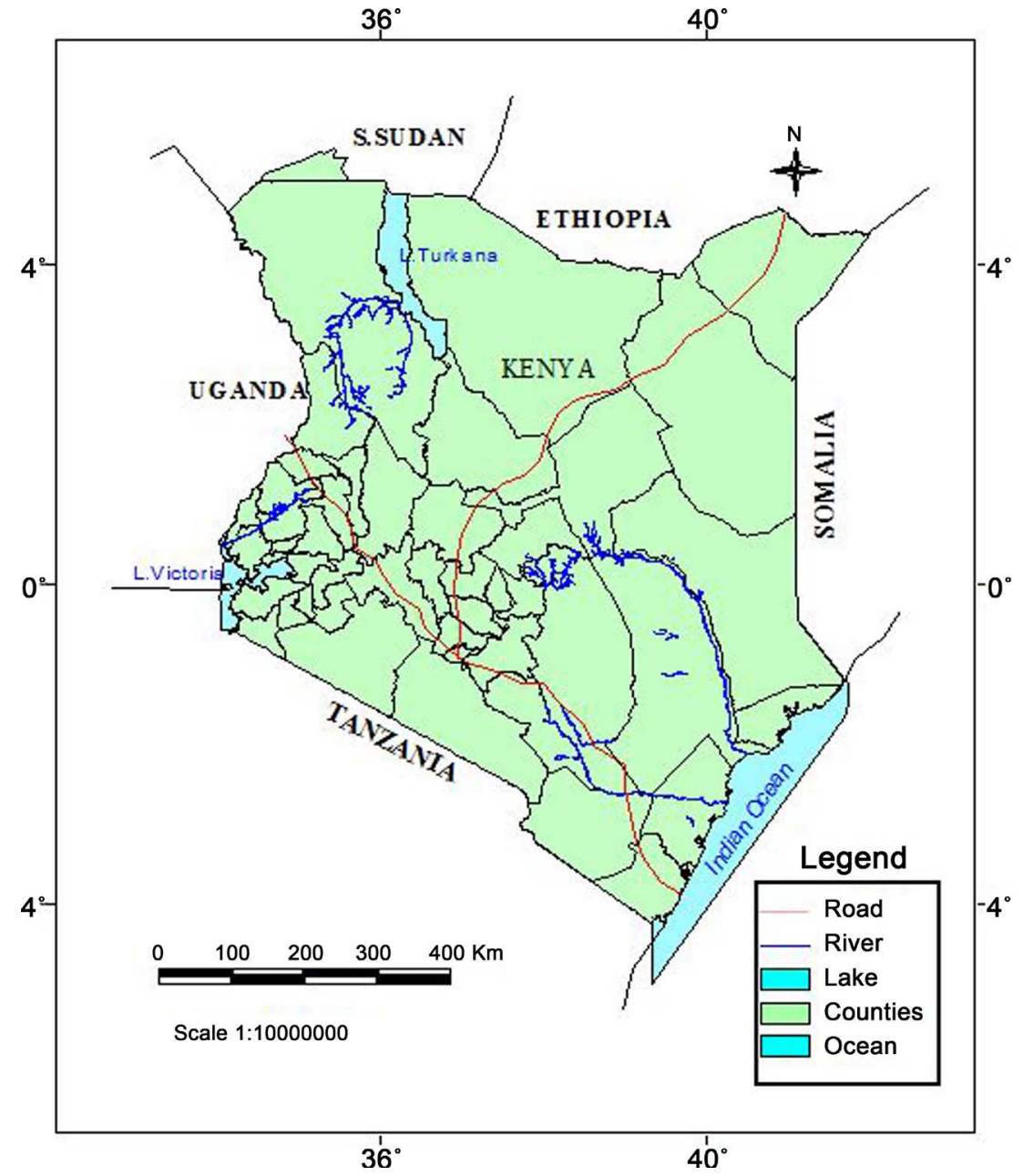

Figure 1. Location map of Kenya (Coordinate system used is Arc 1960 UTM Zone 37s).

and poorly distributed rainfall, these areas are used for pastoral farming [18].

\subsection{Datasets, Sources, Duration and Software Used}

The first step was to identify the variables needed for Spatio-temporal drought characterization. The variables included climate data (Temperature and Precipitation data), Remote sensing satellite data (Advanced Very High Resolution Radiometer and Moderate Resolution Imaging Spectro radiometer images) and Socio economic data of which in this case was maize yield data. These variables were obtained from secondary sources and covered the period from 1986 to 2016. The Remote sensing satellite datasets were from The United States National Aeronautical and Space Administration and were on monthly basis over the study period. The monthly precipitation data was downloaded from (CHIRPS) Climate Hazards Group Infrared Precipitation station, Temperature data on monthly basis was downloaded from Climate Research unit (CRU) and crop production data (maize) in statistical form was acquired from the ministry of Agriculture, livestock and fisheries (Kenya). Table 1 shows the type of data used in the study, sources and the duration. The Software used in processing the data 
included: ERDAS IMAGINE 2013, ARCGIS 10.5, R program and R studio and Microsoft excel 2013.

\subsection{Research Approach}

The methodology approached in this study is shown in Figure 2 using GIS and remote sensing.

\subsection{Data Processing}

\subsubsection{Climate Data}

The climate data used in this study was historical data series of monthly precipitation $(\mathrm{P})$, and monthly temperature which included both maximum and minimum temperature. Precipitation data was from CHIRPS (Climate Hazards

Table 1. Data types, their Sources and the duration.

\begin{tabular}{cccc}
\hline S/No. & TYPE OF DATA & SOURCE & DURATION \\
\hline 1 & NOAA AVHRR(NDVI) & USGS & $1987-2000$ \\
3 & MODIS 13A2 (NDVI) & USGS & $2001-2016$ \\
4 & Topographic map of Kenya & Survey of Kenya & \\
5 & Temperature & Climate Research Unit (CRU) & $1987-2016$ \\
6 & Rainfall & CHIRPS precipitation data & $1987-2016$ \\
7 & Crop yield data & Ministry of Agriculture, Livestock and & $1987-2016$ \\
& (Maize production data) & Fisheries & \\
\hline
\end{tabular}

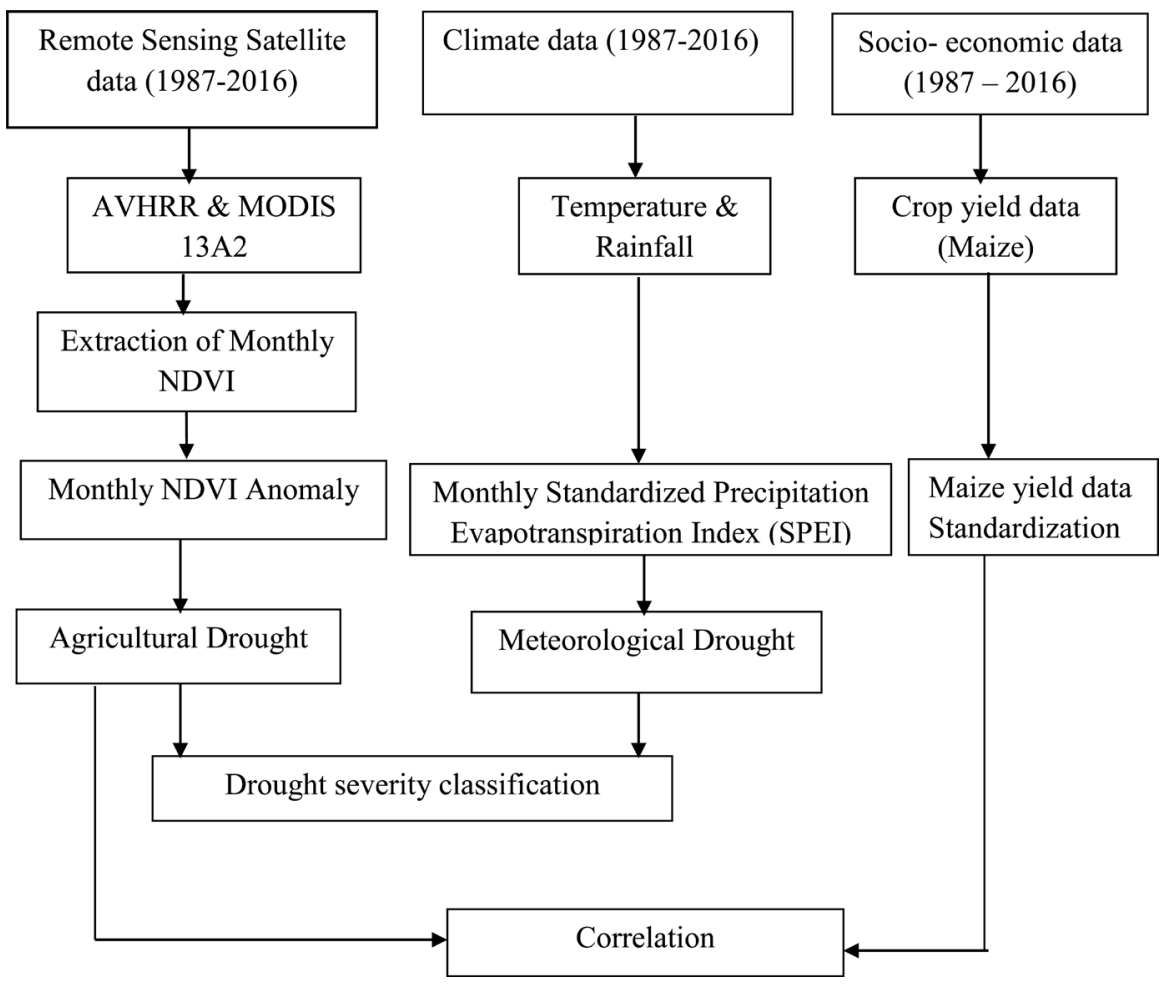

Figure 2. Flowchart illustrating the different steps involved in the drought study. 
Group Infrared Precipitation) for the period 1987 to 2016. Temperature data was downloaded from CRU (Climate Research Unit), both the data was in raster format, the area of interest Kenya was clipped and then converted to text files format so as to get the average monthly rainfall, the minimum, maximum and average temperature. Trend line was used to understand both the temperature and rainfall trends.The rainfall and temperature data was used to calculate SPEI (Standardized Precipitation Evapotranspiration Index). The procedure to calculate the Index was similar to that used for the Standardized Precipitation Index (SPI), but it included the role of temperature as per [19]. The SPEI values computed were in turn used to plot the SPEI temporal trends which were used to identify the drought years and months.

\subsubsection{The Standardized Precipitation Evapotranspiration Index (SPEI)}

Calculation of the Standardized Precipitation-Evapotranspiration Index (SPEI) was done using a time series of the climatic water balance (precipitation minus potential evapotranspiration) so as to get the SPEI values. In this study the equation used was Thornthwaite which computes the monthly potential evapotranspiration (PE) according to [20]. $\mathrm{R}$ program enabled the generation of SPEI timescales values for long term series for Kenya. Moving total time series was constructed from the data computed from precipitation and temperature. The SPEI graphs were used to categorize drought as per [19], drought categories as shown in Table 2. From the graphs, the severely affected dry months and years were identified. SPEI was used as an indicator of meteorological drought. Temperature and rainfall maps of the dry months were then generated for the same to show their spatial distribution in the study area.

\subsubsection{Satellite Data}

The Normalized Difference Vegetation Index (NDVI) was derived from NOAA AVHRR (National Oceanic and Atmospheric Agency Advanced Very High Resolution Radiometer) from 1987 to 2000 and the successor the MODIS level-3 product, MOD13A2 respectively from 2001 to 2016. The data was downloaded from Earth Explorer USGS site. Only the NDVI band was extracted. The first

Table 2. Categorization of Standardized Precipitation Evapotranspiration Index for drought severity classes [19].

\begin{tabular}{cc}
\hline SPEI value & Drought severity class \\
\hline $2.0+$ & Extremely wet \\
1.5 to 1.99 & Very wet \\
1.0 to 1.49 & Moderately wet \\
0.99 to -0.99 & Normal \\
-1.0 to -1.49 & moderately dry \\
-1.5 to -1.99 & Very dry \\
$-2.0+$ & Extremely dry \\
\hline
\end{tabular}


step was to change the NDVI product from Sinusoidal projection, which is not supported in ArcGIS into usable spatial information. All the images were projected into Geographic system with WGS84 datum. NOAA AVHRR data was on monthly basis and image was clipped to area of interest. MODIS NDVI, covered four images which were mosaicked together, the area of interest Kenya was then clipped and then classified using ERDAS IMAGINE and Arc Map 10.2.software. To get the NDVI values the images were converted to text files so as to get the average monthly values which were later used for further analysis.

\subsubsection{Normalized Difference Vegetation Index Anomaly}

NDVI can be used as an index to assess vegetation condition through analysis of NDVI anomaly [21]. In this study, the Vegetative drought index was calculated using NDVI Values. The computed NDVI Anomaly monthly values were correlated with SPEI one and three months lag to get the drought years and affected month. NDVI maps of the dry months were classified to show the spatial distribution of Agricultural drought in the study area.

\subsubsection{Socio Economic Data}

The socio economic data in this study was maize production in tonnes. It was collected from the ministry of Agriculture, Livestock and Fisheries headquarters. The data was organized at different regional levels. The production was computed to see the yield trend over the last 30 years (1987 to 2016). To quantify the impact of drought on production of maize crops in Kenya, the totals were found and were correlated with annual SPEI and NDVI and NDVI Anomaly to assess the impacts of climate change on crops.

\subsection{Data Analysis}

In this study the Standardized Precipitation and Evapotranspiration Index (SPEI) were used to assess the degree of drought in terms of severity, duration and magnitude using observed climate data. In addition, Satellite image based drought indices was used to detect agricultural drought condition and to show its spatial extent. Correlation analysis was done to understand the response of climate and satellite based drought monitoring indices result on crop yield.

\section{Harmonization of Results}

Harmonization as per [23] consisted of decomposition of data sets so as to graphically determine the relationship between them. In this study, the maize production datasets from 1987 to 2016 were summed up and then followed by dividing of each data set for the respective years by the summation of each data set. This then created new standardized data sets for the years under study. The new decomposed data sets were then used in the analysis through graphical representations. In this case scatter plots were used to show the relationships. SPEI and NDVI data was correlated to find the relationship between them in identifying the drought years and months.

Both the NDVI, NDVI Anomaly (Agricultural) drought values, Meteorologi- 
cal (Climatic) data and socio economic data (crop production) which included maize were correlated to find the relationship between Agricultural, meteorological and socio economic data in relation to drought magnitude

\section{Results and Discussion}

\subsection{Temperature and Rainfall Variability in Kenya (1987 to 2016)}

The results in Figure 3 show that both temperature and rainfall have a positive trend, rainfall increases inversely with temperature and most of the months had dry spells with high temperatures.

\subsection{Standardised Precipitation Evapotranspiration Index in Identification of Drought Years and Months}

The Temperature and Rainfall monthly values were used to compute the SPEI values for the whole country from years 1987 to 2016 on monthly basis. The values were then used to plot SPEI trend graphs in which drought years and months were identified as shown in Figures 4-6 respectively. In this study one

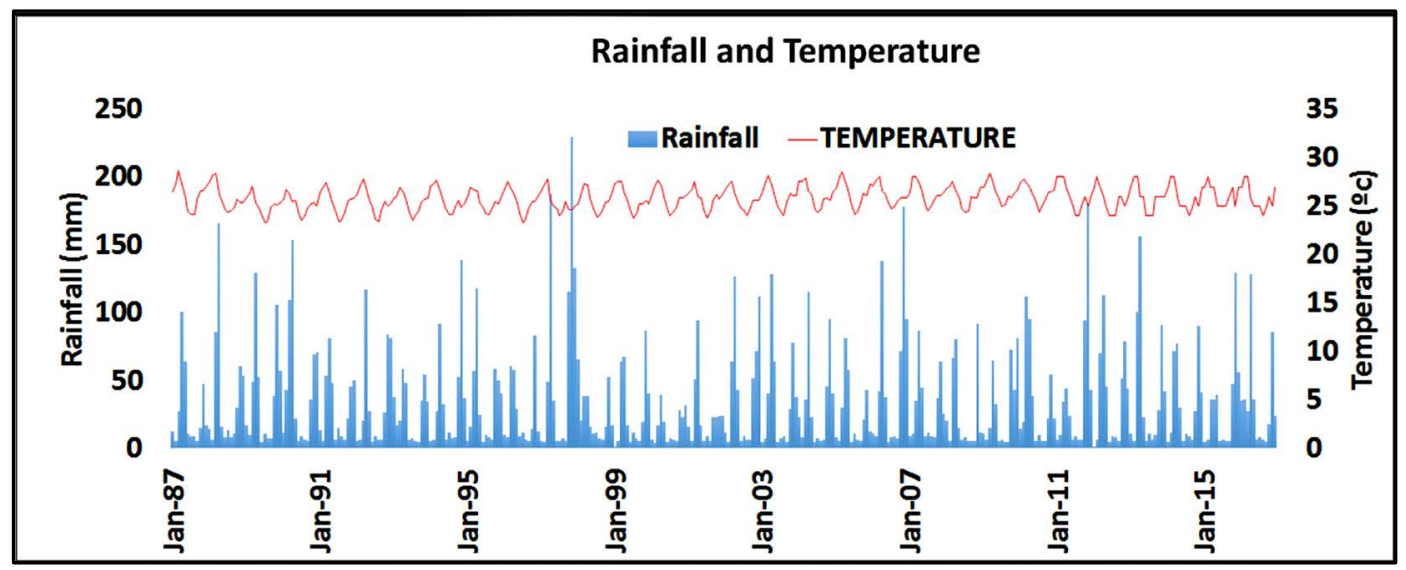

Figure 3. Temporal trends of Rainfall and Temperature showing climate variability in Kenya on monthly basis (1987 to 2016).

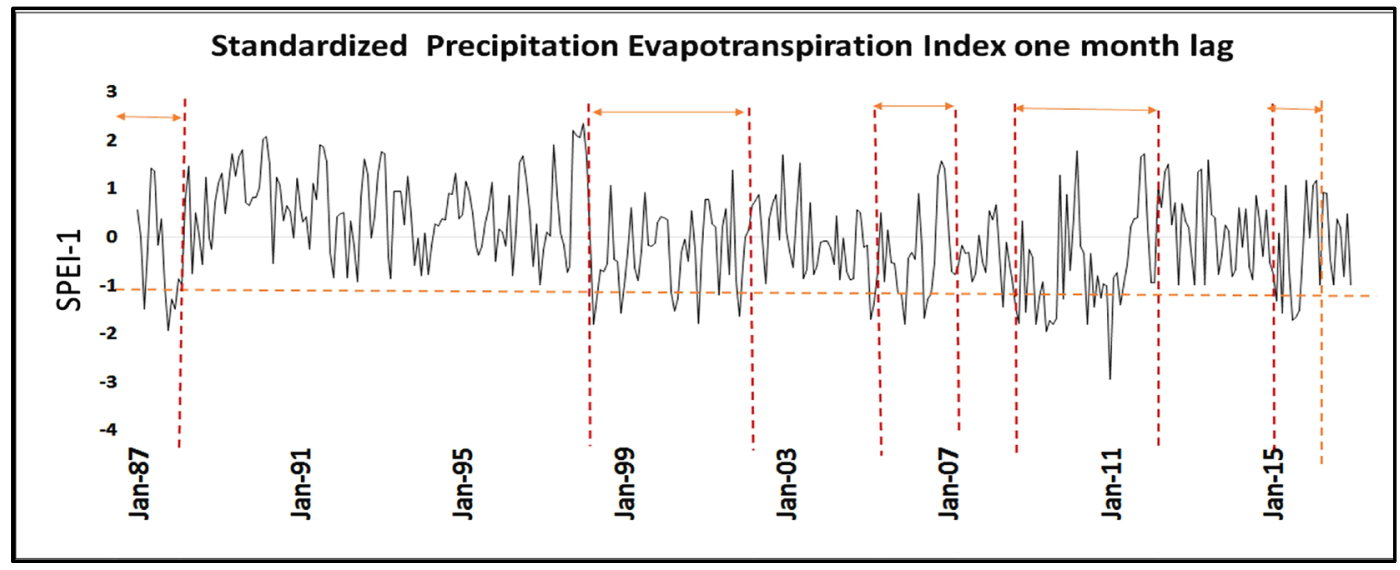

Figure 4. Temporal trends of SPEI one month lag (The arrows show the dry years and months, horizontal dotted line show drought commencement and severity while the vertical dotted line show the duration). 


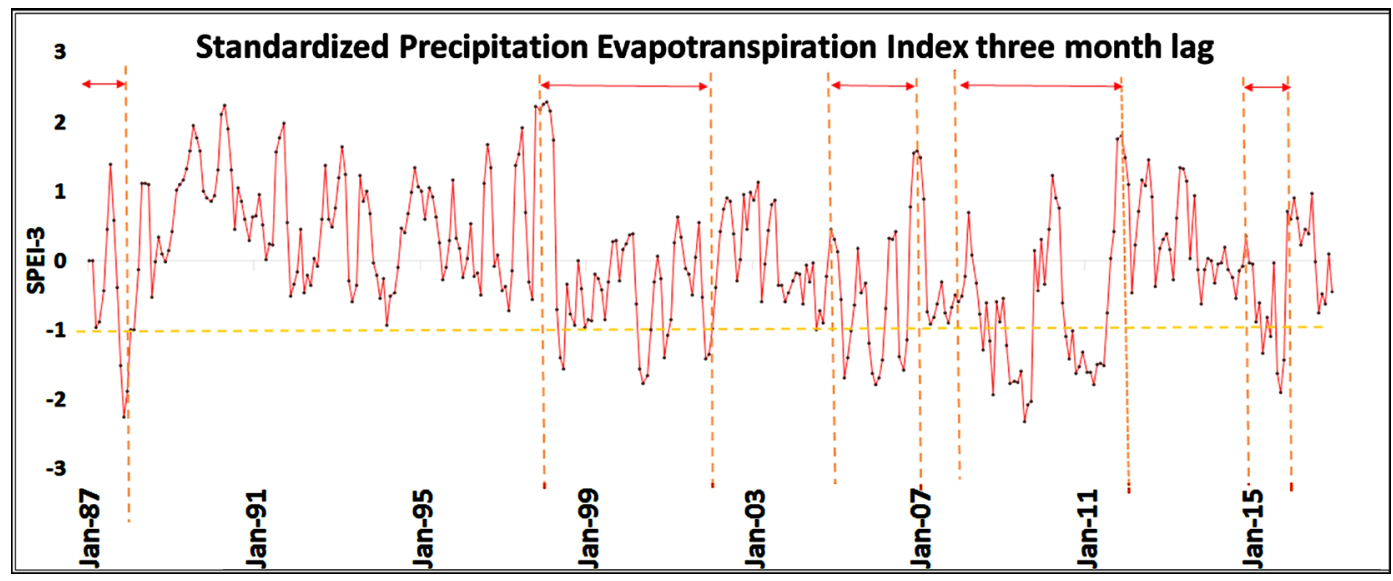

Figure 5. Temporal trends of SPEI three months Lag over the study period (The arrows show the dry years and months, horizontal dotted line show drought commencement and severity while the vertical dotted line show the duration).

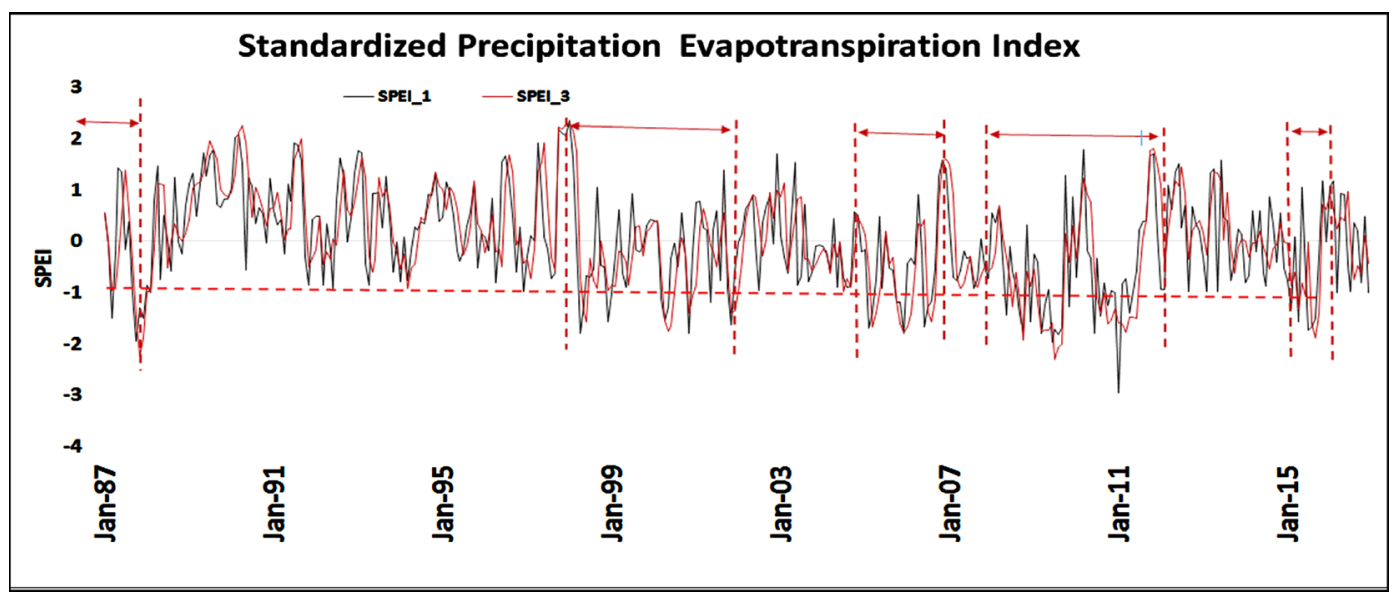

Figure 6. Temporal trends of SPEI one and SPEI three months lag over the study period (The arrows show the dry years and months, horizontal dotted line show drought commencement and severity while the vertical dotted line show the dura.

month and three months scales time series were used in the analysis. The one and three month SPEI values reflected short- and medium-term moisture conditions and provided a seasonal estimation of precipitation deficiency. A drought is noted whenever the SPEI value reached a value of -1 and continued until the SPEI value became positive again. The drought was categorized as per [19] as shown in (Table 2). From the results in Figures 4-6 drought years were identified as 1987, 1998, 2000, 2001, 2005, 2006, 2008, 2009, 2010, 2011 and 2015. Categorization of SPEI for drought severity was done using [19] seven drought classes. The drought months were characterized as being Extremely dry (below $-2)$, very dry $(-1.5$ to -1.99$)$ and moderately dry ( -1 to -1.49$)$. The dotted horizonatal line shows the drought commencement value ( -1 and below).

\subsection{Normalized Difference Vegetation Index (NDVI)}

Figure 7 shows that NDVI has a positive trend and the values increase or de- 
crease in association to the vegetation cover. NDVI values lies between -1 to +1 with negative values indicating clouds and water, Positive values near zero indicating bare soil, and higher positive values of NDVI ranging from sparse vegetation $(0.1$ to 0.5$)$ to dense green vegetation 0.6 and above. The results in Figure 8 shows that there is about one to three months' time lag between SPEI and NDVI. Since there is a certain time lag between NDVI and SPEI, decrease in NDVI associates with the decreasing amounts of plant cover. The time interval between a precipitation event and the time when precipitated water reaches plants' root and affect plant growth can vary from 1 to 12 weeks depending on vegetation and soil types [24]. Figure 9 shows that there is a correlation as the SPEI three months lag decreases, the NDVI values also decreases with some months in the lag.

\subsection{Normalized Difference Vegetation Index Anomaly in Agricultural Drought Characterization}

NDVI Anomaly values were used to characterize agricultural droughts using the

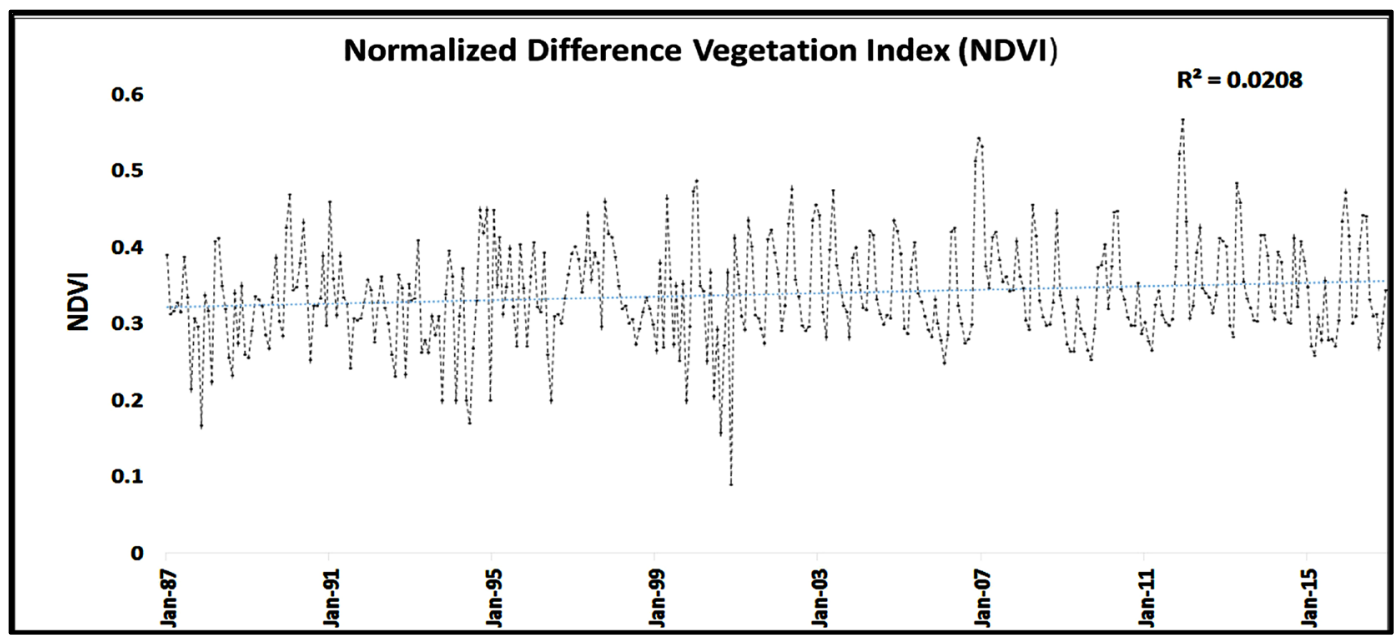

Figure 7. Temporal trends of NDVI values over the study period (1987-2016).

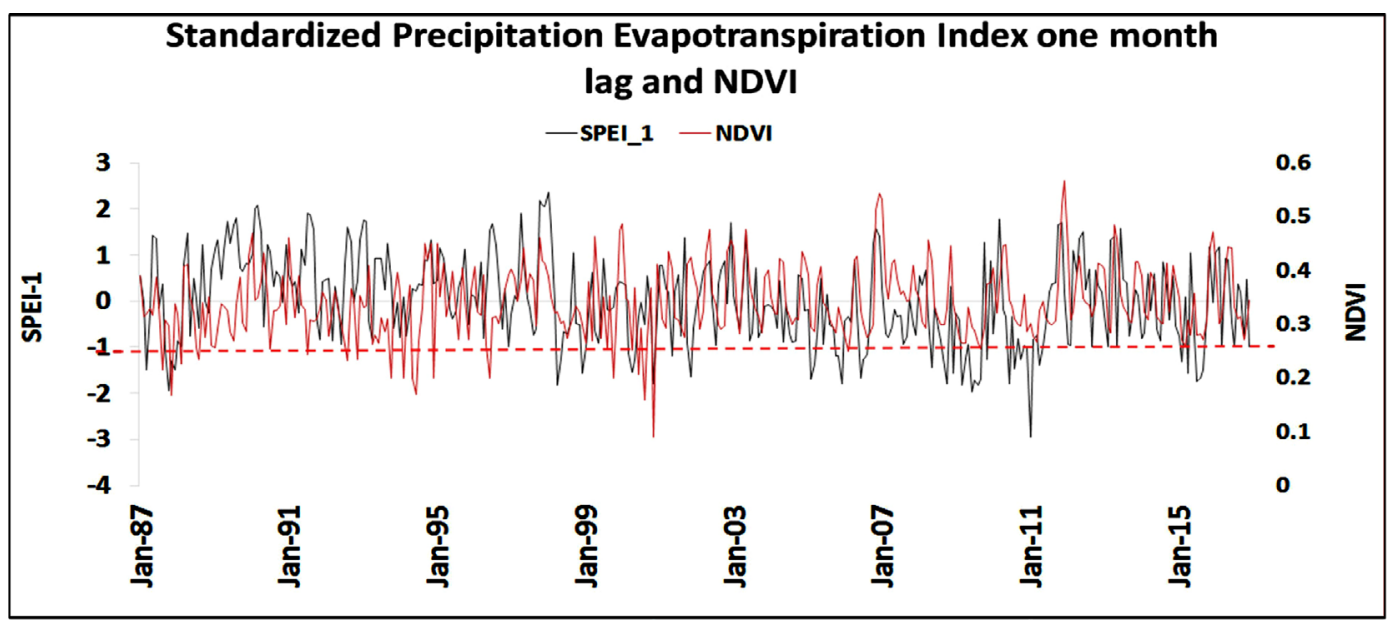

Figure 8. Temporal trends of SPEI one month lag and NDVI over the study period (1987-2016). 
drought categories in Table 3. Results in Figure 10 show that the identified drought years were 1987, 1989, 2000, 2001, 2005, 2006, 2008, 2009, 2011 and 2015. Within the figure, the drought years and months are shown by the arrows, the severity is depicted by the horizontal dotted lines using the Agricultural drought risk classification in Table 3, where drought severity commences from 0 and below. While the vertical dotted line, shows the drought duration. The severely affected months are shown in Figure 13.

\subsubsection{NDVI Anomaly and Standardized Precipitation Evapotranspiration Index in Drought Characterization}

The results in Figure 11 and Figure 12 show the drought years and months

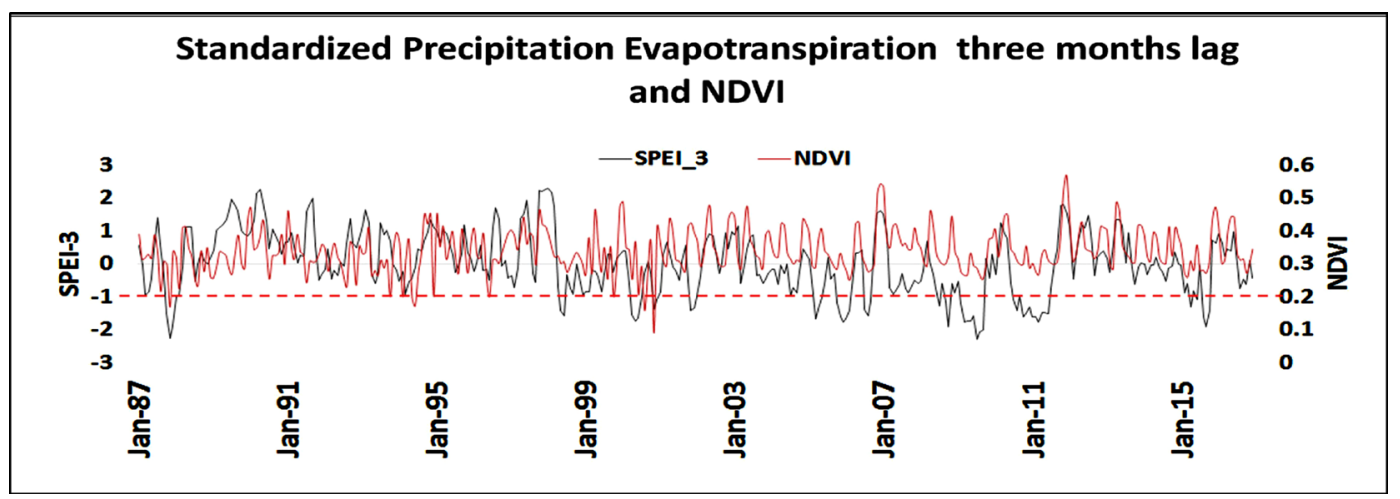

Figure 9. Temporal trends of SPEI three months lag and NDVI over the study period (1987-2016).

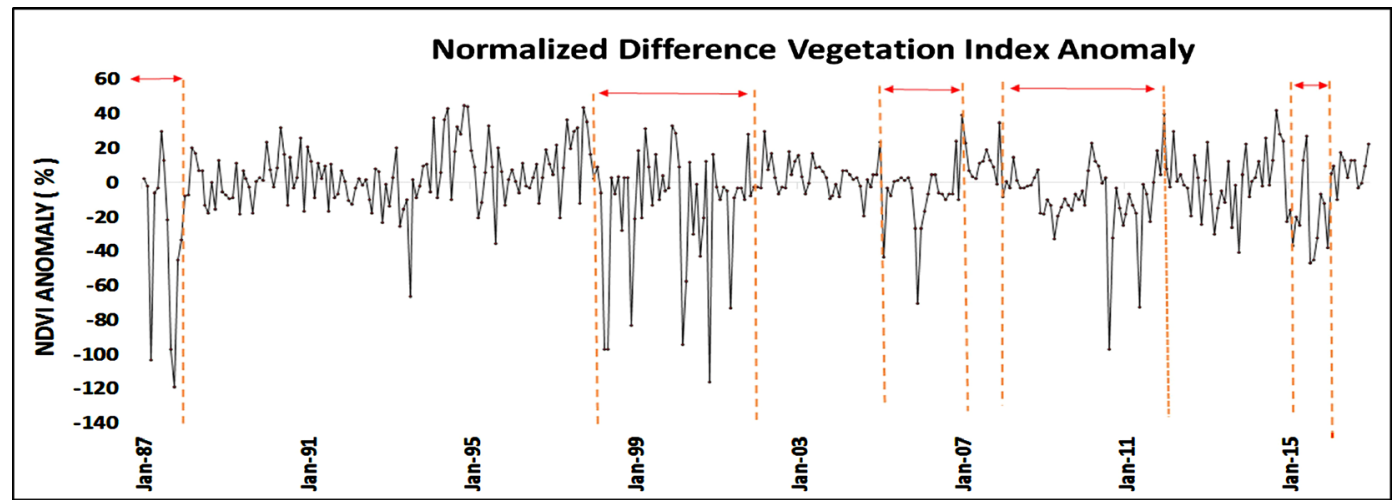

Figure 10. Temporal trends of NDVI anomaly over the study period (The arrows show the dry years and months, horizontal dotted line show drought commencement and severity while the vertical dotted line show the duration).

Table 3. Agricultural drought risk classification using NDVI anomaly [22].

\begin{tabular}{cc}
\hline NDVI anomaly (\%) & Drought severity class \\
\hline Above 0 & No drought \\
0 to -10 & Slight drought \\
-11 to -25 & Moderate drought \\
26 to -50 & Severe drought \\
Below -50 & Very Severe drought
\end{tabular}




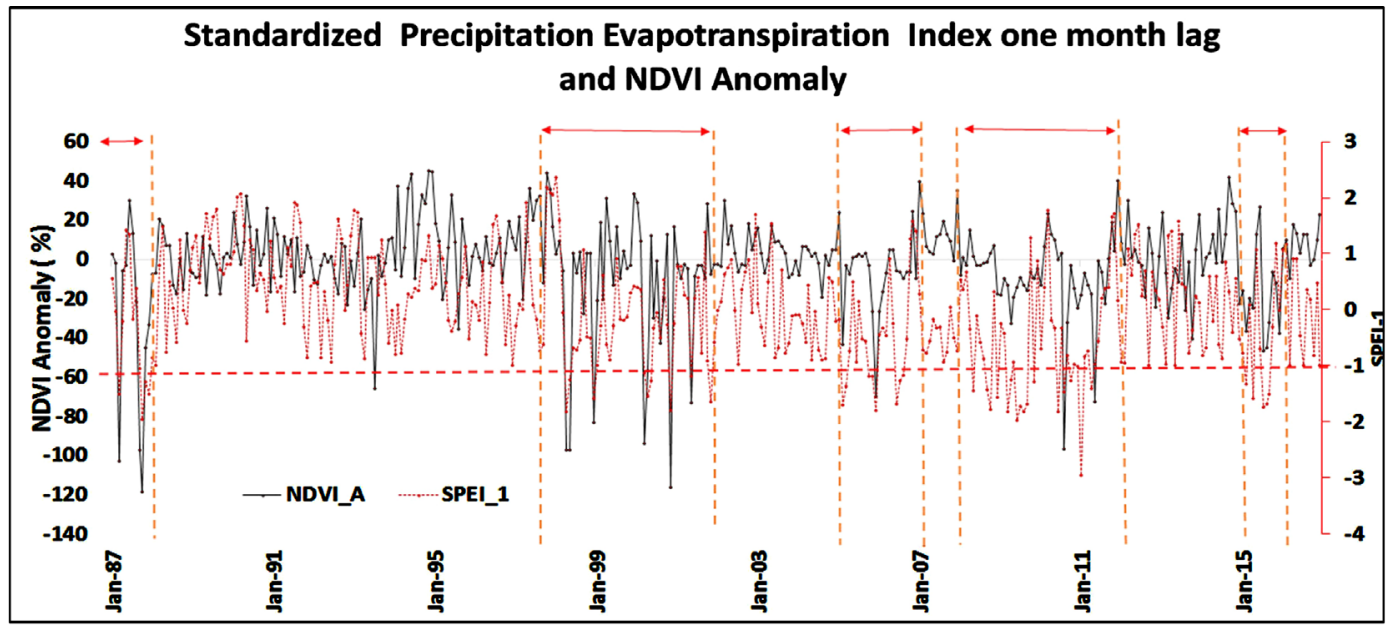

Figure 11. Temporal trends SPEI one month lag and NDVI anomaly over the study period (The arrows show the dry years and months, horizontal dotted line show drought commencement and severity while the vertical dotted line show the duration).

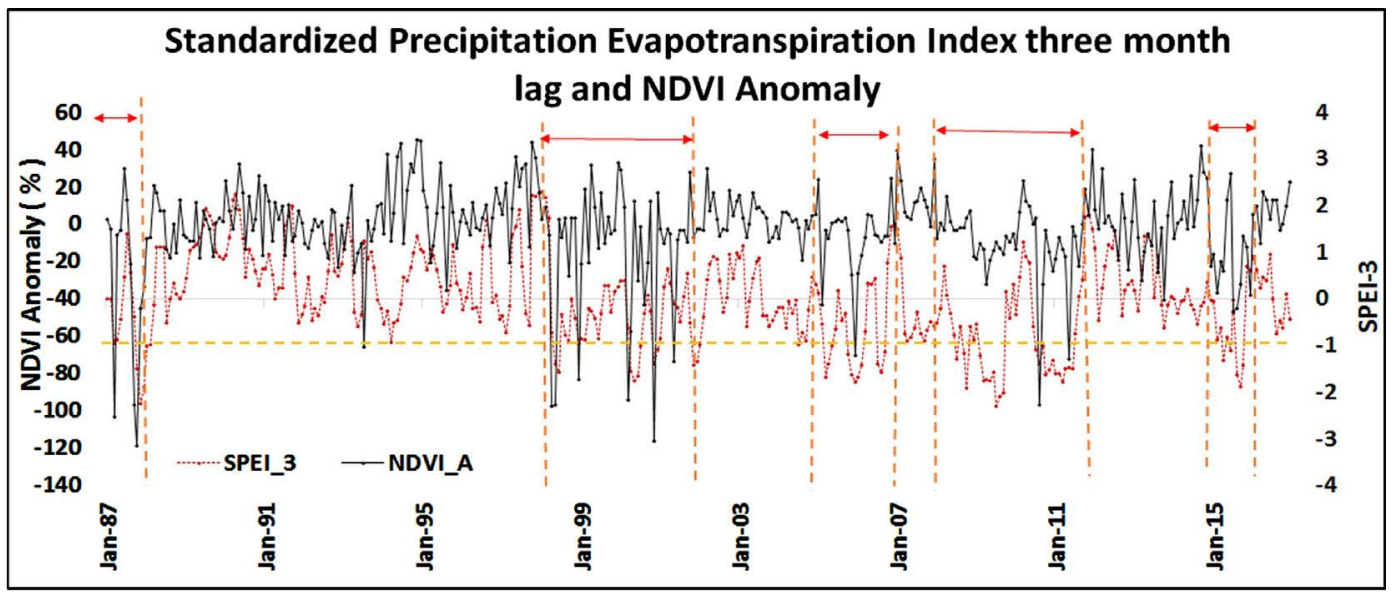

Figure 12. Temporal trends of SPEI three month lag and NDVI anomaly over the study period (The arrows show the dry years and months, horizontal dotted line show drought commencement and severity while the vertical dotted line show the duration).

identified by correlating NDVI Anomaly with SPEI one and three months lag respectively. The arrows show the drought years and months, the vertical dotted lines show the duration and the characterization of the event, while the horizontal dotted line show the severity (below it being commencement of drought). The 1987 drought was characterized as short Severe drought year for it covered five months with the severely affected month being October.

1998 to 2001 was characterized as prolonged moderate drought years, for all the consecutive four years had dry spells. In 1998 three months were affected, the month of April being severely affected and characterized as a very dry month. The year 2000 had four dry months the severely affected month being November and the year 2001 had two months that were affected, the severely affected months being November and characterized as very dry.

2005 and 2006 were characterized as a mild drought duration. 2005 had five 
drought months with the severely affected months being December characterized as a very dry month. 2006 had two dry months, the severely affected month being June and was characterized as a very dry month.

2008 to 2011 were characterized as prolonged severe drought duration. 2008 had four dry months, the severely affected month was October having been characterized as a very dry month. 2009 had 7 dry months, the severely affected month being June (Extremely dry month). 2010 had four dry months, the severely affected month being June (very dry month). 2011 had two dry months, June was the severely affected (extremely dry month).

2015 was a short mild drought year with five dry months. Severely affected month was August. Results show, either short rains or long rains failed or both in the dry years over the study period.

The results are in agreement with some of the results of [25] who characterized drought years in his study as 1984, 1992, 1993, 2000, 2001, 2005, 2006 and 2009 [11]. 2008, 2009, 2010 and 2011 and [14] as 1987, 1993 and 2004. The years 1984, 1992, 1993 and 2004 and 1998 have discrepancies. This was because the earlier authors did not put into consideration the effects of temperature increase on drought conditions [14]. Study did not cover the whole country but a small region.

\subsubsection{Normalized Difference Vegetation Index Anomaly Maps for Agricultural Drought}

The results in Figure 13 shows the severe drought months in the drought years. The level of drought severity ranged from slight to very severe in both drought years. The results show non uniformity distribution of drought in the study area during the study period. The maps show that though a month had been classified as being dry, some areas still had some greenness, this is shown in all the maps. In the study period the areas that were most affected were ASAL (Arid and semi-Arid regions) of the country. The periods October 1987, November 2001, June 2010 and July 2015 despite them being dry years and severely affected months, some areas still had some greenness. This may be due to the NDVI time lag. The time interval between a precipitation event and the time when precipitated water reaches plants' root and affect plant growth varies from one to twelve weeks depending on vegetation and soil type for the dry periods [24].

\subsection{Maize Production Trends Nationally in Kenya from 1987 to 2016}

Figure 14 shows maize productions in Kenya nationally, between 1987 to 2016 . The years 1987, 1998, 2000, 2001, 2005, 2006, 2008, 2009, 2010, 2011 and 2015 had low production. This correlates well with the drought years identified using SPEI and NDVI Anomaly.

\subsection{Correlation Analysis of Results}

NDVI and SPEI one month lag relate well as shown in Figure 15(a). $\left(\mathrm{R}^{2}=0.26\right)$, where $\mathrm{R}=0.51$, this implied that within 30 years' data, $51 \%$ of SPEI one month 


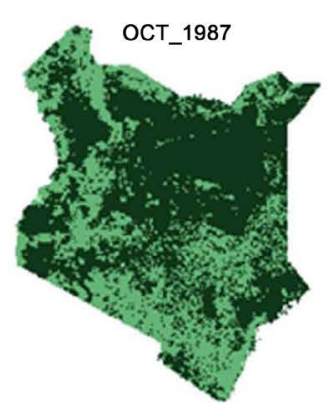

DEC_2005
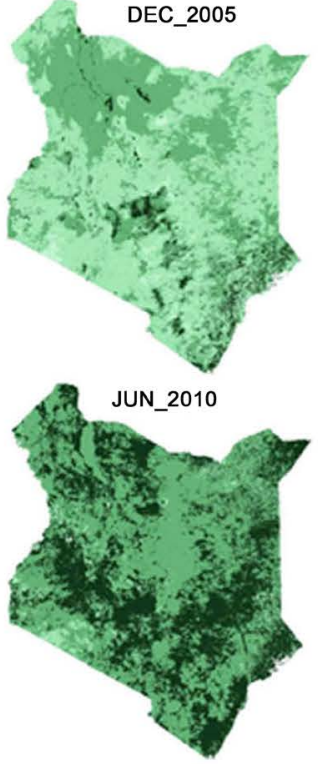
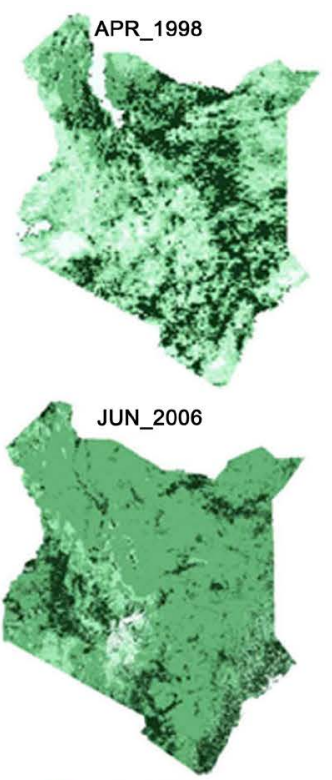

JUN_2011

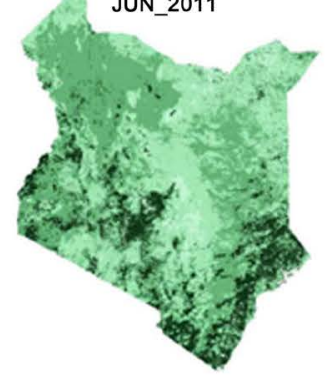

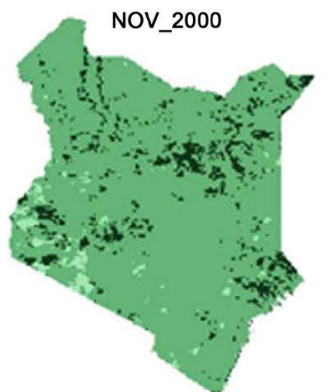
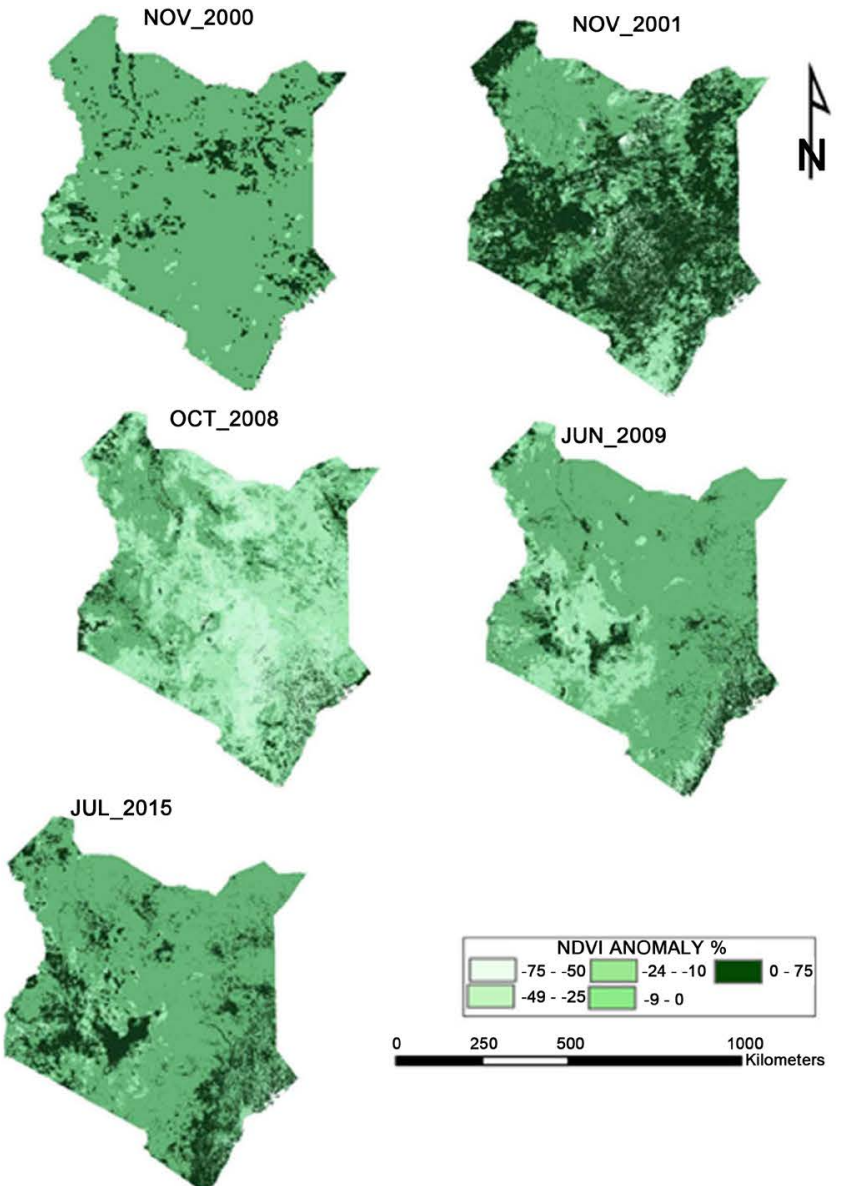

Figure 13. Normalized Difference Vegetation Index Anomaly maps showing the spatial distribution of Agricultural drought in the severely affected months within the drought years (1987 to 2016).

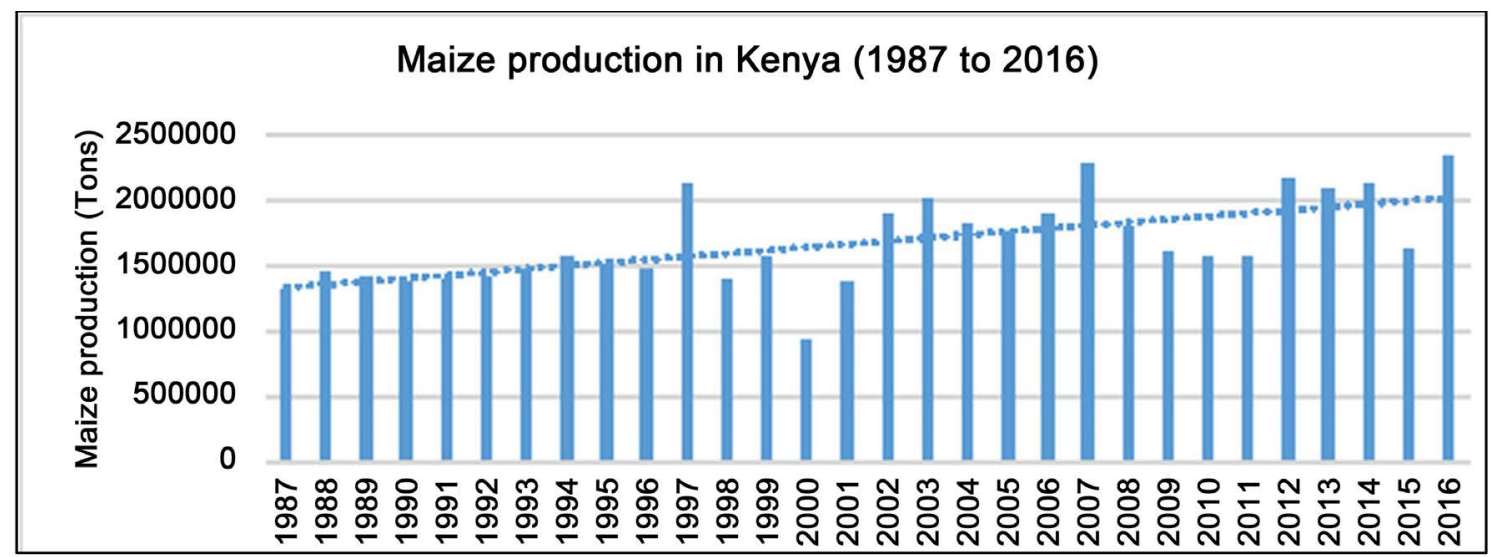

Figure 14. Maize production in Kenya (1987 to 2016).

lag variable can be explained by NDVI. The relationship between SPEI three months lag and NDVI as shown Figure 15(b) shows that NDVI correlates with SPEI three month lag. $\left(R^{2}=0.3213\right)$, where $R=0.566$. This shows that they also have a better relationship in that within 30 years' data, $57 \%$ of SPEI three month lag variable can be explained by NDVI. 

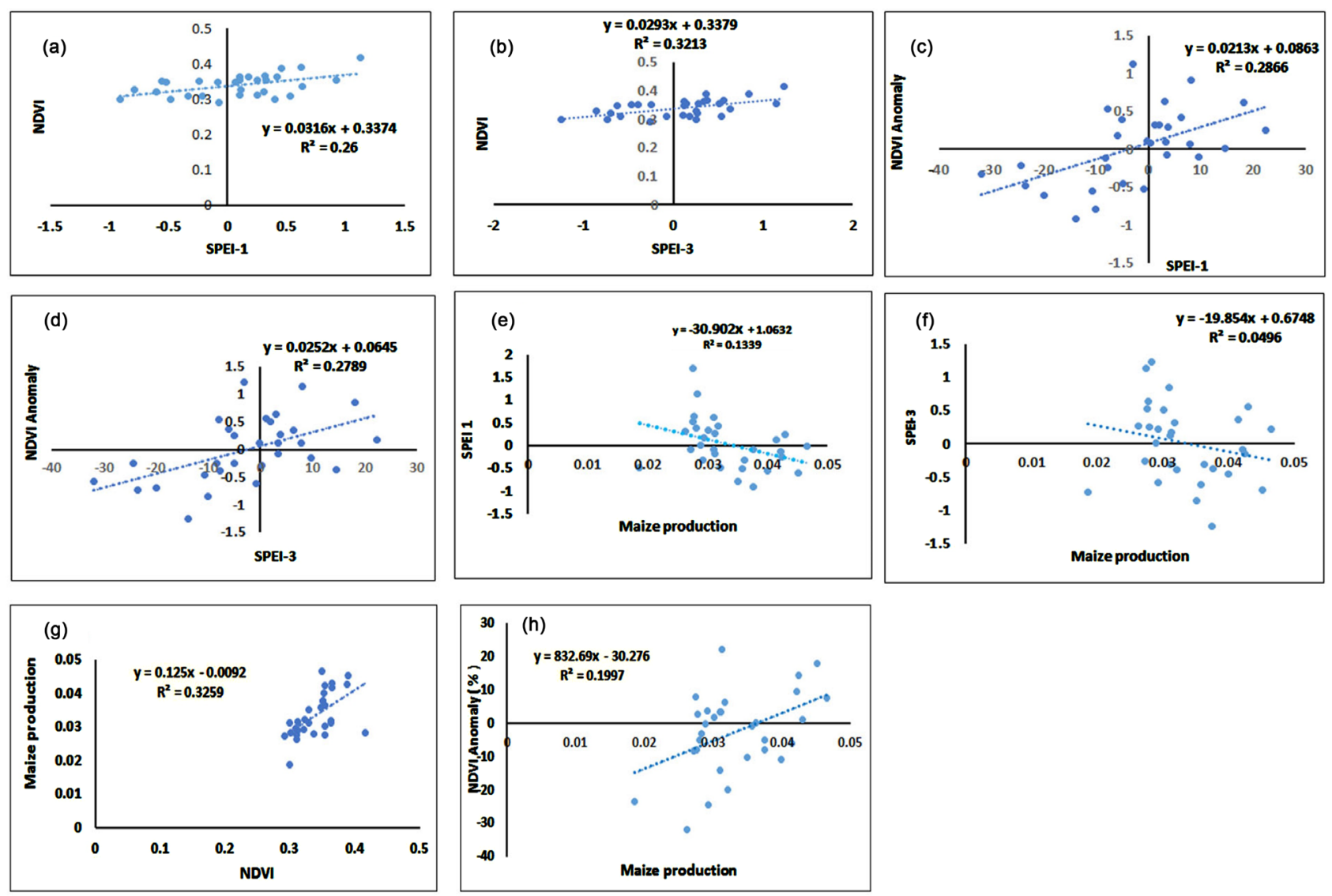

Figure 15. Correlation Analysis: (a) SPEI one month lag vs NDVI; (b) SPEI three month lag vs NDVI; (c) NDVI Anomaly vs SPEI one month lag; (d) NDVI Anomaly vs SPEI three month lag; (e) SPEI one month lag vs maize yield; (f) SPEI three month lag vs maize yield; (g) NDVI vs maize yield; (h) NDVI Anomaly vs maize yield.

Figure 15(c) show that NDVI Anomaly and SPEI one month lag has a good relationship in which $\left(R^{2}=0.2866\right)$ where $R=0.54$. Therefore $54 \%$ of NDVI Anomaly variable within the study period of 30 years can be used to explain SPEI one month lag. Figure 15(d) show that NDVI Anomaly and SPEI three month lag has an association in which $\left(R^{2}=0.2789\right)$, where $R=0.55$. Therefore $55 \%$ of NDVI Anomaly variable within the study period of 30 years can be used to explain SPEI three month lag. The results in Figures 15(a)-(d) revealed that the relationship established between the variables was strong and in line with the findings of [19] who reported a strong correlation between the SPEI, NDVI and NDVI Anomaly. [26] concluded that NDVI Anomaly was more strongly related to climate variables (precipitation and temperature).

The results in Figure 15(e) show that SPEI one month lag has some relationship with maize yield. $\left(R^{2}=0.1339\right)$ where $R=0.37$. In this case, within 30 years' study period, $37 \%$ of SPEI one month lag variable can be explained by maize yield of the same time. SPEI three months lag and maize yield were correlated and the results in Figure 15(f) showed that when SPEI is positive, maize yield increases revealing a good positive correlation $(\mathrm{R}=0.24)$. The results revealed in Figure 15(e) \& Figure 15(f) showed that the relationship between the two va- 
riables was positive. SPEI is an index that represents water and temperature deficit or excess. Positive SPEI show that water has been available to plants leading to above normal condition yields, whereas, negative SPEI is reflected through yield reduction. This result is in line with [27] who reported a good correlation between yield Anomaly and SPEI.

NDVI has a strong relationship with Maize yield. Figure 15(g) shows that for the 30 years study period, $\left(\mathrm{R}^{2}=0.3259\right)$ where $\mathrm{R}=0.57$. Therefore $57 \%$ of NDVI variable can be explained by maize yield. Figure 15(h) shows that there is a strong relationship between NDVI Anomaly and maize yields. $\left(R^{2}=0.19997\right)$, where $\mathrm{R}=0.45$. Therefore $45 \%$ of NDVI Anomaly variable within the 30 years of the study period can be used to explain maize yields. Results in Figure 15(h) and Figure 15(g) show that the strength of the index to explain the existence of agricultural drought through maize yield is relatively good. The result of this study is consistent with the findings of [28] who reported a good correlation between NDVI and crop yield

\section{Conclusions and Recommendation}

\subsection{Conclusions}

The drought years identified in this study were 1987, 1998, 2000, 2001, 2005, 2006, 2008, 2009, 2010, 2011 and 2015 with months being characterized as being extremely dry, very dry and moderately dry for meteorological drought using SPEI while for Agricultural drought they were characterized as slight, moderate and severe drought using NDVI Anomaly. The correlation analysis of SPEI and NDVI showed that SPEI drought detection has one month lag compared to NDVI. NDVI lag those of SPEI. SPEI correlates well with NDVI Anomaly.

1987 was a short and severe drought year with a total magnitude of -7.2 , the months affected were five with the severely affected month being October with -1.9 severity.

1998 to 2001 was characterized as prolonged moderate drought event. It covered three months in 1998 with a magnitude of -3.8; the month of April was characterized as a very dry month with a severity of -1.6 . The year 2000 had four months with a magnitude of -5.7 , the severely affected month was November with -1.8 and the year 2001 had two months that were affected with a magnitude of -2.8 , the severely affected month being November with the severity of -1.6 .

2005 and 2006 were characterized as mild drought event. 2005 had five drought months with overall magnitude of -7.3 , the severely affected month was December with severity of -1.8 and characterized as a very dry month. 2006 had 2 month of drought with a magnitude -4.2 , the severely affected month was June having severity of -1.7 and was characterized as a very dry month.

2008 to 2011 was characterized as a prolonged severe drought year event. 2008 had four dry months with a magnitude of -6.2 , the severely affected month was October with severity of -1.8 (very dry month). 2009 had 7 dry months with 
magnitude of -11.5 , the severely affected month was June with severity of -2.0 (Extremely dry month). 2010 had four dry months with a magnitude of -5.6 ; the severely affected month was June with a severity of -1.8. 2011 had two dry months with a magnitude of -4.4 , January was the severely affected month with a magnitude of -3.0 and characterized as an extremely dry month.

2015 was a short mild dry year event with five dry months with an overall magnitude of -6.3 . Severely affected month was August with a severity of -1.7 . From the results it can be concluded that either short rains or long rains failed or both.

Drought trends in Kenya do not have a fixed pattern and tend to fluctuate from time to time, this is shown from the rainfall, temperature and SPEI graphs. The rainfall, temperature and NDVI maps of the dry years and months show that there is non-uniformity in dryness where some areas along the coast, western, Nyanza and Rift valley tend to be wet whereas the ASAL (Arid and Semi-Arid Lands) that forms about $80 \%$ of the total Kenya's land cover are always dry. This has led to effects of non-uniformity in drought detection.

Agricultural drought similarly does not have a fixed trend. This is seen through NDVI and maize production graphs. However maize production fails in different regions due to non-uniform drought occurrence, this is because regions fall under different hydrological basins which experience different climatic conditions at different times.

\subsection{Recommendation}

The long term historical records of satellite imagery and climatic data have become essential tools in calculating drought severity levels and to determine drought risk prone areas. Similarly this study has achieved a great milestone in the Agriculture sector as mitigation measures can be put in place long before the occurrence of drought. This would reduce loss of livestock and human life as a result of loss of water and food.

Due to availability of satellite imageries agriculture has benefited due to constant drought assessment levels. Government agencies and County based Departments can create drought mitigation plans based on drought monitoring data models.

Drought modelling using meteorological index (SPEI) was not done in this study. This is because meteorological drought index lack spatial extent as such requires many points which are interpolated to model drought. In this study data used was for the whole country which was only a one point data (Kenya). For future research, I recommend for further studies that would be done using the same technology according to hydrological basins.

Future studies should also use same methods to predict future drought in Kenya.

\section{Acknowledgements}

I express my heartfelt thanks to my supervisors, Dr. Arthur W. Sichangi and Dr. 
Godfrey O. Makokha for their guidance during the entire project phase, my family for the financial support and all the organizations who provided data for this research.

\section{References}

[1] UNISDR (2009) Drought Risk Reduction Framework and Practices: Contributing to Hyogo Framework for Action. United Nations Secretariat of the International Strategy for Disaster R Education, 197 p.

[2] Crafts, A. (1968) Water Deficits and Physiological Processes. In: Kozlowski, T.T., Ed., Water Deficits and Plant Growth. Plant Water Consumption and Response, Vol. II, Academic Press, New York, 85-133.

[3] Mishra, A.K. and Singh, V.P. (2010) A Review of Drought Concepts. Journal of Hydrology.

[4] Mwangi, E.W.F. (2014) Forecasting Droughts in East Africa. Hydrology and Earth Science, 18, 611-620. https://doi.org/10.5194/hess-18-611-2014

[5] Damberg, L.A. (2013) Global Trends and Patterns of Drought from Space. Springer-Verlag, Wien.

[6] Belal, A.R. (2012) Drought Risk Assessment Using Remote Sensing and GIS Techniques. Arabian Journal of Geosciences, 7, 35-53.

https://doi.org/10.1007/s12517-012-0707-2

[7] Nagarajan, N. (2009) Drought Assessment. Springer, New Delhi.

[8] Benson, C. and Clay, E. (1998) The Impact of Drought on Sub-Saharan African Economies. World Bank Technical Paper No. 401, The World Bank, Washington DC, $80 \mathrm{p}$.

[9] Mortimore, M.J. and Adams, W.M. (2001) Farmer Adaptation, Change and "Crisis" in the Sahel. Global Environmental Change, 11, 49-57. https://doi.org/10.1016/S0959-3780(00)00044-3

[10] Lyon, B. and Dewitt, D. (2005) A Recent and Abrupt Decline in the East African Long Rains. Drought and Water Crisis: Science, Technology and Management Issues. CRC Press, Boca Raton, 71-92.

[11] Zwaagstra, L.S.Z. (2010) An Assessment of the Response to the 2008-2009 Drought in Kenya. A Report to the European Union Delegation to the Republic of Kenya., International Livestock Research Institute, Nairobi.

[12] Suryabhagavan, K.V. (2017) GIS-Based Climate Variability and Drought Characterization in Ethiopia over Three Decades. Weather and Climate Extremes.

[13] Agutu, N.O., et al. (2017) Assessing Multi-Satellite Remote Sensing, Reanalysis, and Land Surface Models' Products in Characterizing Agricultural Drought in East Africa. Remote Sensing of Environment, 194, 287-302. https://doi.org/10.1016/j.rse.2017.03.041

[14] Changwony, C. (2017) Using GIS and Remote Sensing in Assessment of Water Scarcity in Nakuru County, Kenya. Advances in Remote Sensing, 6, 88-102. https://doi.org/10.4236/ars.2017.61007

[15] SEDAC (2005) Gridded Population of the World, Version 3 (GPWv3). Columbia University and Centro International de Agricultural Tropical: Center for International Earth Science Information Network.

[16] UN (2009) The Millenium Development Goals. United Nations, New York.

[17] Uwechue, R. (1996) Africa Today. Africa Books Limited, London. 
[18] FEWSNET (2010) Kenya: Food Security Framework. United States Agency for International Development, Washington DC.

[19] Vicente, S.B. (2010) A Multiscalar Drought Index Sensitive to Global Warming: The Standardized Precipitation Evapotranspiration Index. Journals of Climate, 23, 1696-1718. https://doi.org/10.1175/2009JCLI2909.1

[20] Thornthwaite, C.W. (1948) An Approach toward a Rational Classification of Climate. Geography Review, 38, 55-94. https://doi.org/10.2307/210739

[21] Murali, K.G. (2008) Remote Sensing Based Agricultural Drought Assessment in Palar Basin of Tamil Nadu State, India. Journal of the Indian Society of Remote Sensing, 37, 9-20.

[22] Legesse, G. and Suryabhagavan, K. (2014) Remote Sensing and GIS Based Agricultural Drought Assessment in East Shewa Zone, Ethiopia. Tropical Ecology, 55, 349-363.

[23] Jacob Shadiva Simeon, C.N. (2017) Assessing the Environmental Impacts of Post Eatec Wattle Tree Plantations in Eldoret Municipality. International Journal of Life Sciences Research, 5, 28-36.

[24] Li, B., Tao, S. and Dawson, R.W. (2002) Relation between AVHRR NDVI and Ecoclimatic Parameters in China. Inter-National Journal of Remote Sensing, 23, 989-999. https://doi.org/10.1080/014311602753474192

[25] Osbahr, H.A. (2006) Linking Climate Change Adaptation and Disaster Risk Management for Sustainable Poverty Reduction. Kenya Country Study. A Study Carried out for the Vulnerability and Adaptation Resource Group (VARG) with Support from the European Commission.

[26] Wang, J., Price, K.P. and Rich, P.M. (2001) Spatial Patterns of NDVI Response to Precipitation and Temperature in the Central Great Plains. International Journal of Remote Sensing, 22, 3827-3844. https://doi.org/10.1080/01431160010007033

[27] Taotao, C.G. (2016) Assessment of Drought Impact on Main Cereal Crops Using a Standardized Precipitation Evapotranspiration Index in Liaoning Province, China. Sustainability, 8, 1069.

[28] Beyene, E. (2007) Drought Assessment for Nile Basin Using Meteosat Second Generation Data with Special Emphasis on the Upper Blue Nile Region. Msc Thesis, ITC, Enschede. 